\title{
2056 Quantitative magnetic resonance first-pass perfusion analysis in hypertrophic cardiomyopathy. Intrastudy variability Rory O'Hanlon*1, Chiara Bucciarelli-Ducci ${ }^{1}$, Agata Grasso1, Ali Alsafi², Rick Wage ${ }^{1}$, Meghana Kulkarni ${ }^{1}$, Peter Gatehouse ${ }^{1}$, Michael Roughton ${ }^{2}$, Dudley J Pennell ${ }^{1}$ and Sanjay K Prasad ${ }^{1}$
}

Address: ${ }^{1}$ Royal Brompton Hospital, London, UK and ${ }^{2}$ Imperial College, London, UK

* Corresponding author

from I th $^{\text {th }}$ Annual SCMR Scientific Sessions

Los Angeles, CA, USA. I-3 February 2008

Published: 22 October 2008

Journal of Cardiovascular Magnetic Resonance 2008, I0(Suppl I):A325 doi:I0.I I86/I532-429X-I0-SI-A325

This abstract is available from: http://jcmr-online.com/content/I0/SI/A325

(c) 2008 O'Hanlon et al; licensee BioMed Central Ltd.

\begin{abstract}
Aims
Microvascular perfusion abnormalities in hypertrophic cardiomyopathy (HCM) are important markers of prognosis and may act as a trigger for arrhythmic events. Magnetic resonance first pass perfusion is a validated noninvasive imaging tool for the assessment of microvascular dysfunction by the quantification of myocardial perfusion reserve indices (MPRI). There are limited data available for the intrastudy and interstudy reproducibility of quantification using commercially available software. We sought to determine the intrastudy variability for MPRI in patients with HCM.
\end{abstract}

\section{Methods}

We performed adenosine first-pass stress and rest perfusion on 26 patients with HCM on a 1.5 T Siemens Avanto scanner at our institution. A 3 slice hybrid-EPI sequence was used (TR $5.8 \mathrm{~ms}, 30^{\circ}$, ETL $4,1860 \mathrm{~Hz} /$ pixel, $2.8 \times 2.8 \times 8 \mathrm{~mm}$ voxels over typically $360 \times 270 \mathrm{~mm}$ FOV (adapted per patient) at TI $=110-140 \mathrm{~ms}$ after BIR- 4 saturation for each of the 3 fat-suppressed slices per cycle, using TSENSE (R2, coil profiles average 8)). Gadolinium dose used for first-pass was $0.1 \mathrm{mmol} / \mathrm{kg}$ injected as a bolus at $7 \mathrm{~mL} / \mathrm{sec}$ followed by a $15 \mathrm{~mL}$ saline flush through a power injector. In the $1^{\text {st }} 50 \mathrm{~ms}$ of the perfusion scan, a low resolution FLASH image was acquired to determine the blood signal (arterial input function) in order to determine the MPRI. A single observer, blinded to patient clinical data, analyzed each perfusion study at two sepa- rate time points to reduce bias. For perfusion analysis, the epi and endocardium was manually delineated and the myocardium was divided into 16 segments according to the ACC/AHA model. Each segment was subdivided into endocardial and epicardial segments and MPRI were calculated using customized software (CMRTools, Cardiovascular Imaging Solutions, London, UK).

\section{Results}

Coefficients of variation were calculated as the standard deviation of the differences between the two measurements divided by the mean value, and comparison of values was calculated using a Bland-Altman plot (Figure 1). In total, 825 segments were compared for agreement and sub analysis was performed to determine if greater intrastudy variability occurred in different segments. In general there was a good agreement between all segments between analysis dates, with a coefficient of variability of $34 \%$ for all segments. There was no significant difference in agreement on a segment by segment basis. Agreement was greater for MPRI values which are considered abnormal $(<2.5)$ and this may be relevant for analysis of abnormal perfusion studies. See table in Figure 2.

\section{Conclusion}

Microvascular perfusion abnormalities are common in HCM and may represent a novel therapeutic target. The spatial resolution on CMR perfusion is such that changes in perfusion values over time or in response to therapies 


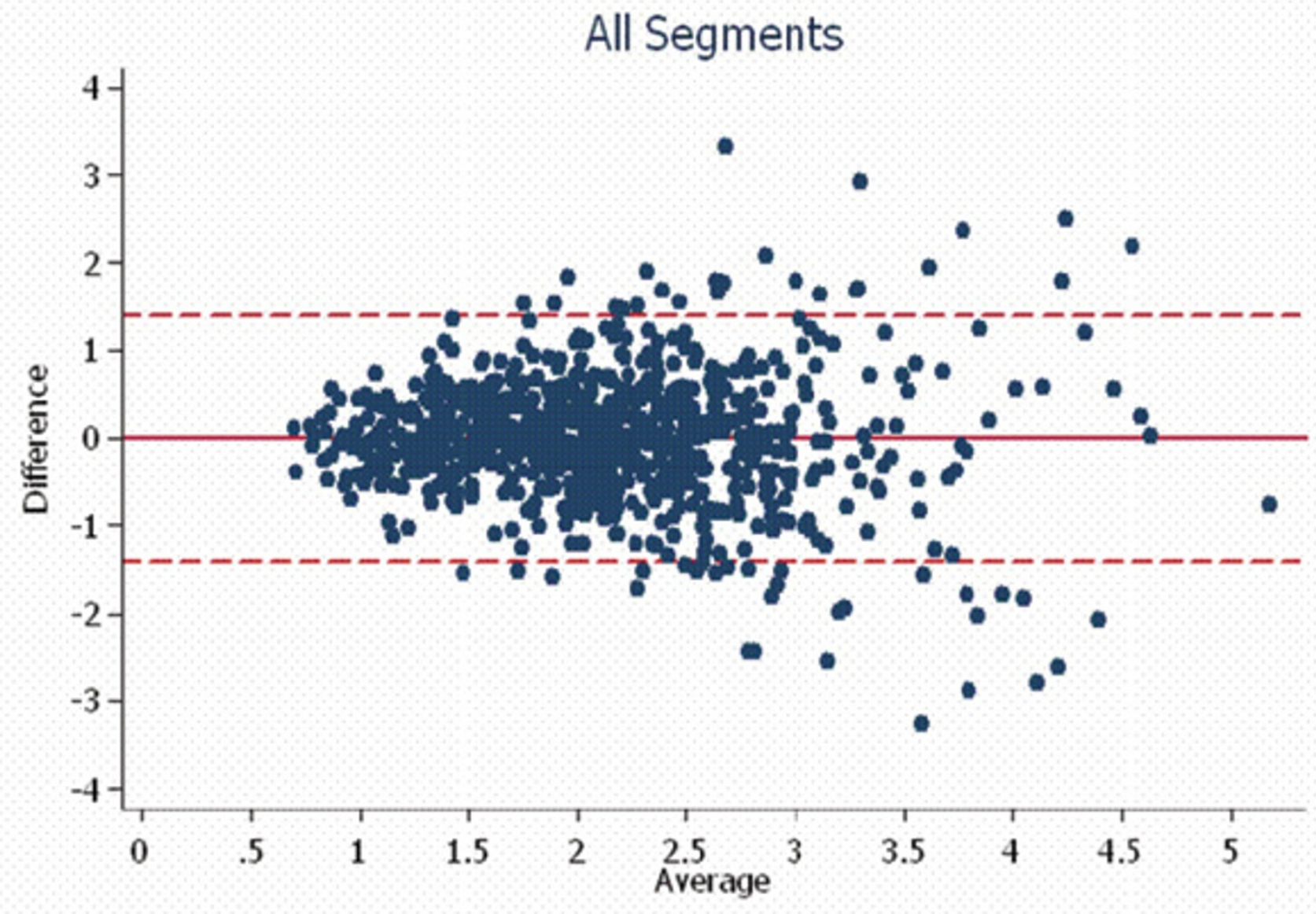

Figure I

Bland Altman plot of intrastudy agreement in MPRI analysis for 825 myocardial segments in hypertrophic cardiomyopathy.

may be reliably and reproducibly quantified. In order to power any study assessing changes in MPRI over time, it is important to know the intrastudy and interstudy variability of the technique. We have determined the intrastudy variability for myocardial perfusion reserve index analysis patients with HCM undergoing adenosine stress MR perfusion, which an important step in potentially following values over time. 


\begin{tabular}{|l|c|c|cc|c|}
\hline Area & $\begin{array}{c}\text { Mean } \\
\text { Difference }\end{array}$ & $\begin{array}{c}\text { SD of } \\
\text { Difference }\end{array}$ & \multicolumn{2}{|c|}{$\mathbf{9 5 \%}$ LoA } & CoV \\
\hline Enda Anterior & 0.04 & 0.63 & -1.20 & 1.28 & $32 \%$ \\
Enda Inferior & 0.01 & 0.85 & -1.66 & 1.67 & $42 \%$ \\
Enda Lateral & 0.01 & 0.71 & -1.39 & 1.41 & $34 \%$ \\
Enda Septal & -0.02 & 0.52 & -1.04 & 1.00 & $27 \%$ \\
Epi Anterior & -0.15 & 0.78 & -1.68 & 1.37 & $36 \%$ \\
Epi Inferiar & -0.11 & 0.76 & -1.60 & 1.37 & $34 \%$ \\
Epi Lateral & 0.06 & 0.82 & -1.55 & 1.67 & $35 \%$ \\
Epi Septal & -0.01 & 0.68 & -1.34 & 1.31 & $32 \%$ \\
\hline All Segments & -0.01 & 0.72 & -1.42 & 1.39 & $34 \%$ \\
\hline
\end{tabular}

Figure 2

Table of segmental MPRI variability for 825 myocardial segments in hypertrophic cardiomyopathy.

Publish with Bio Med Central and every scientist can read your work free of charge

"BioMed Central will be the most significant development for disseminating the results of biomedical research in our lifetime. "

Sir Paul Nurse, Cancer Research UK

Your research papers will be:

- available free of charge to the entire biomedical community

- peer reviewed and published immediately upon acceptance

- cited in PubMed and archived on PubMed Central

- yours - you keep the copyright
BioMedcentral 